\title{
Developing Sign Displays for Conveying Information ${ }^{1}$
}

\author{
Anna M. Prizzia, Mark E. Hostetler, and Martin B. Main²
}

Educational signs can be an effective means of providing information. Especially when observers are engaged in other activities (e.g., walking, golfing, rest area stops), educational signs may be a preferred, non-intrusive method of delivering information. The educational signs you design can help to inform and empower people to make better decisions about their behaviors and practices, but in order to do so the design and message must be effective.

There are a number of key principles for creating effective educational materials. These fit within four main stages:

\section{Planning}

\section{Preparation \& Creation}

\section{Testing \& Revision}

\section{Implementation \& Evaluation}

The purpose of this document is to provide an overview of these four stages in creating educational sign displays. As an illustration of this process, we discuss sign displays designed for homeowners in a residential community (Figure 1). These displays were part of an environmental education program that informed homeowners about natural resource conservation issues.

\section{Planning}

Planning is an important step in creating successful sign displays. Taking time to plan will make displays more effective and can minimize work spent revising the displays. To begin the planning process, create an outline that contains deadlines for completing each of the four stages. This will give you an overall timeline for the project. Next, answer who, what, how, when and where.

\section{1) Who is the target audience?}

Answering this question will help you define the needs and expectations of your audience. It will shape your program by focusing the material on a particular group with specific needs and issues that could be addressed. For example, you should approach your topic differently depending on whether your target audience is children, adults, or university professors. For our project, the target audience was middle school to adult residents within a planned community.

1. This document is WEC 180 and is one of a series of the Department of Wildlife Ecology and Conservation, Florida Cooperative Extension Service, Institute of Food and Agricultural Sciences (IFAS), University of Florida. First published: May 2004. Please visit the EDIS Web site at http://edis.ifas.ufl.edu for more publications.

2. Anna M. Prizzia, former graduate student; Mark E. Hostetler, Wildlife Extension Specialist and Assistant Professor; Martin B. Main, Wildlife Extension Specialist at Research and Education Center--Immokolee; Dept. of Wildlife Ecology and Conservation, Florida Cooperative Extension Service, Institute of Food and Agricultural Science, University of Florida, Gainesville, FL 32611.

The Institute of Food and Agricultural Sciences (IFAS) is an Equal Employment Opportunity - Affirmative Action Employer authorized to provide research, educational information and other services only to individuals and institutions that function without regard to race, creed, color, religion, age, disability, sex, sexual orientation, marital status, national origin, political opinions or affiliations. For information on obtaining other extension publications, contact your county Cooperative Extension Service office. Florida Cooperative Extension Service / Institute of Food and Agricultural Sciences / University of Florida / Larry R. Arrington, Interim Dean 


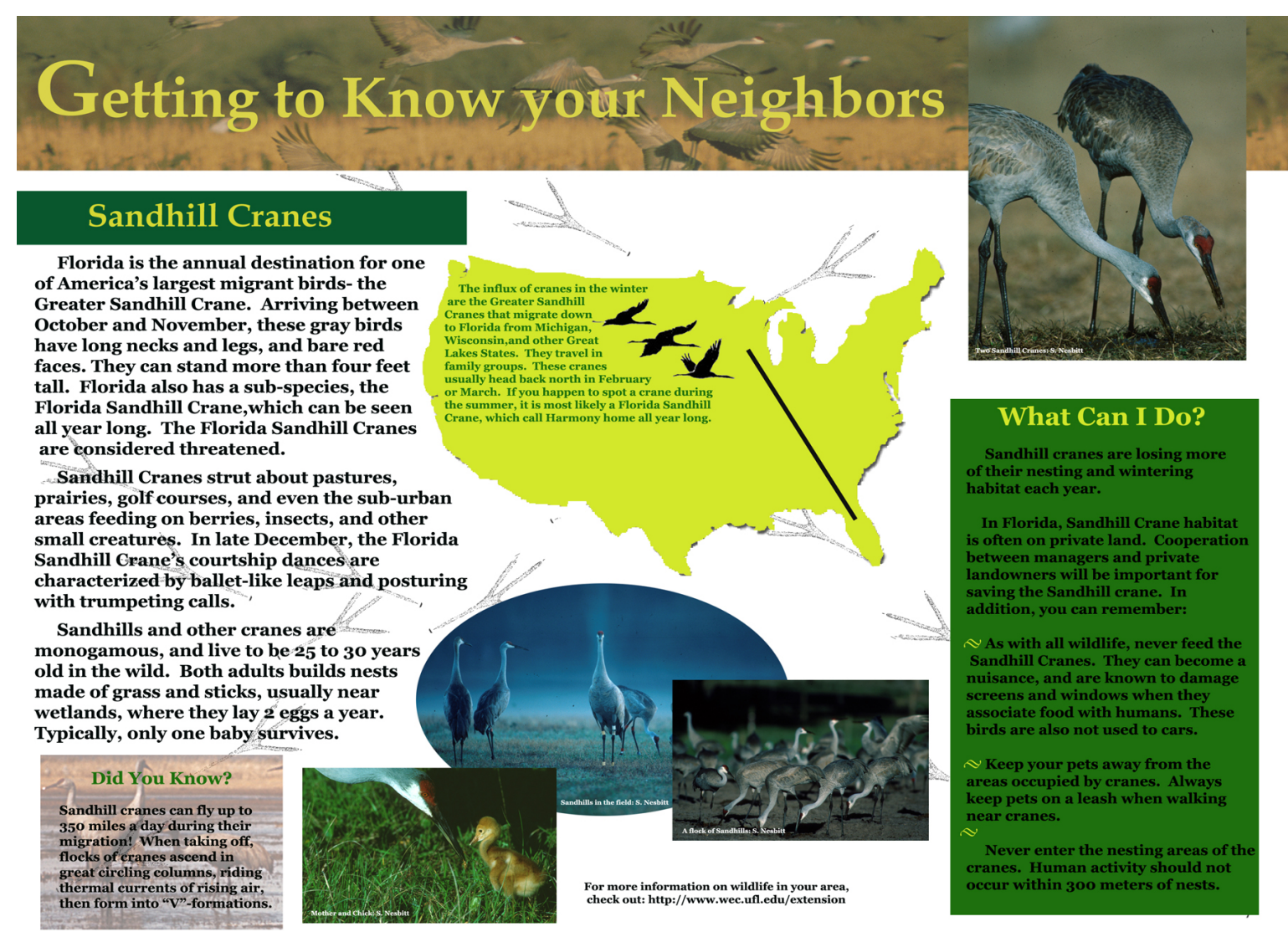

Figure 1. Example of sign display placed in a residential community. Credits: Anna M. Prizzia

\section{2) What do you hope to accomplish with your sign displays and what information should you include on them?}

Clarifying your goals will help in determining what goes on the displays. The more specifically you define your goal, the more directly you will address that goal with your display, which will increase the likelihood that your effort will be effective. For example, in the residential community, our goal was for residents to understand more about natural resources and ways to conserve resources in their homes, yards, and neighborhoods. We wanted residents to become more aware and knowledgeable about natural resources. We wanted residents to have positive attitudes and increased participation in natural resource conservation.

Deciding on what issues to address and include on the signs is important. You have only a limited amount of space on each sign. One way to determine what information to include is to get feedback from both professionals and the target audience. In our project, we conducted focus groups with environmental professionals and homeowners. For each group, we asked what types of environmental information they would like to see on the signs.

A useful technique to help clarify goals is to create a theme. There are three steps to identifying a theme. First, identify a broad topic (e.g., backyard wildlife). Second, narrow your topic (e.g., backyard wildlife habitat). Third, write out your theme statement as a complete sentence (e.g., Creating backyard habitat for birds, butterflies, and other wildlife is fun and easy). By developing a theme as a complete sentence, it is easier to maintain focus on your objectives and develop your educational display accordingly.

\section{3) How will you convey the message?}

Answering this question will help you decide how the information will be presented on the sign. Make a list of all you know about your target audience. For example, where do they work? What 
level of education do they have? This will help you make key decisions about how to present information. Also, what kind of structure will hold the sign and how big? Will it be a simple sign or a large structure with a roof? For our project, each sign had a theme (Figure 1) and all signs had a catchy title, basic background information, a highlighted issue, and a "what you can do" section. Because the same people will walk by these signs each week, we made these signs dynamic. Informational panels could be switched out throughout the year.

\section{4) Where will the signs be displayed and when will you put them up?}

You need to explore the most appropriate places for people to view the signs. Where is people traffic the highest? Where will people have the time and inclination to read the sign? When the signs go up can be important, too. For example, the signs may coincide with an event or recent issue. In our project, we placed signs along a public walking trail in the neighborhood. We plan to alternate the signs in the display to coincide with seasonal changes.

\section{Preparation and Creation}

After you have carefully planned out who, what, when, how, and where for your materials, you can begin the creation process. Usually, this can be simply gathering information. Check to see if other materials are available that meet identified needs. Using valuable sources of existing information and graphics can save money and time. Other states or government agencies are usually willing to provide camera-ready art in exchange for a printed acknowledgment. All materials from the federal government are "public domain" and free to be reproduced, with credit. We made four-colored panels and borrowed photos and art from a variety of agencies and people.

You will also need computer software to make the sign. We utilized Adobe Photoshop ${ }^{\circledR}$ to make our signs. This program was most useful as it could handle text and photos. Many software programs are available. Be sure to check which programs best suit your interests and are compatible with local printing companies.
What type of sign will hold the information? There are many different models of signs and companies that will build them. Depending on the information, you can use big or small signs. The display can be made out of wood, aluminum, or plastic. The text and photos could be printed with a variety of different inks. Signs can be engraved or printed panels. Any kind of sign can be made, depending on your goals and budget. For example, aluminum signs are the most expensive, but also the most durable.

Of note, you may want change information on the sign periodically. To make this type of sign, you need to construct a display that allows information panels to be replaced. Panels that contain information printed with sunlight-resistant inks and laminated can easily be taken out of the display and replaced with a new one. These dynamic signs are useful in Florida because the color of any sign will deteriorate within 5 years due to the sun. Printing new information panels is much cheaper than replacing the full sign. In our project, the signs were outdoors and people were going to walk by these signs frequently. Thus, we installed dynamic signs (48" X 36").

\section{Testing and Revision}

Pre-testing your materials with the intended audience provides an opportunity to check the effectiveness of your message while it is still in development. Does your audience understand the message? Do they like the design of the sign? Pre-testing doesn't have to be complicated or expensive. But if you wait too long to ask these important questions, you may have to start over.

You can also do a peer/expert review of the content to test accuracy and content, but this cannot substitute pre-testing a draft with several members of the target audience. Pre-testing will let you know if the message is clear and if it is perceived as important. Some questions to ask in the test include:

-What is the main point of this material?

- What part of this do you find unclear or confusing? 
- Is the material attractive? Is there anything that is hard to see or understand?

- Tell me what this graphic is showing.

- What would make your family, friends, or neighbors more likely to read this information?

Pre-testing with approximately 15-20 people usually gives enough information to make reasonable decisions, but the amount of pre-testing depends on the complexity or difficulty of your message.

Pre-testing can be done as many times as you need during development. Graphics, photos, other design elements and translations should all be pre-tested. A general uniformity of responses will let you know if your message is clear. Some common ways to pre-test messages include focus groups, individual interviews, and self-administered questionnaires (Figure 2).

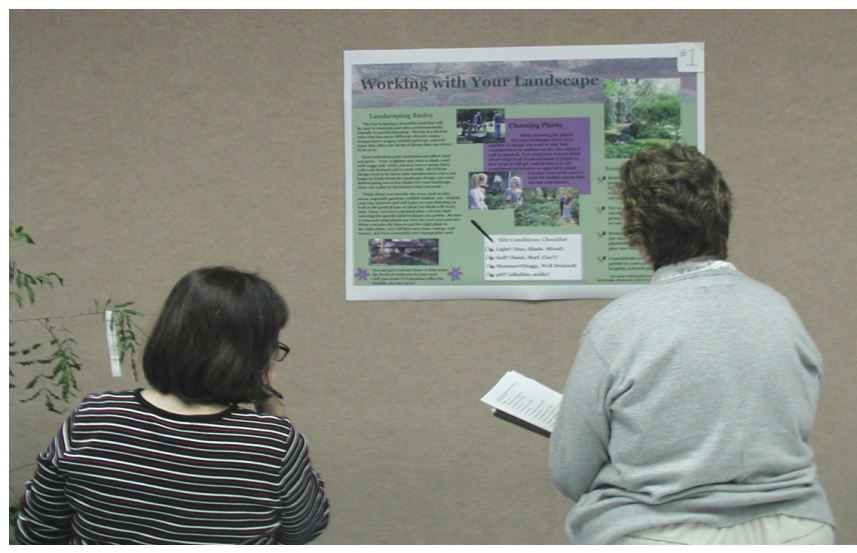

Figure 2. Homeowers review sign displays that will be placed in residential communities. Such reviews, or focus groups, help determine if your educational materials are effective at delivering your intended message. Credits: Anna M. Prizzia

\section{Implementation and Evaluation}

After planning, creating, and pre-testing your work, the final step is implementation and evaluation. This is the step where you install the signs and evaluate their impact. Include monitoring and evaluation of your materials. Monitoring and evaluating will help you assess the initial results and long-term impacts. This process will also provide feedback from your target audience that can be used to modify the signs. A few techniques that can be used for evaluation are discussion, participant observation, and surveys or questionnaires conducted both pre- and post-deployment of the signs.

\section{Summary}

Creating sign displays can be a challenge, but following these stages of development will help make your time and effort pay off. With careful planning, preparation/creation, testing/revision, and implementation/evaluation, you can have effective educational materials that will make your work easier and will help you achieve your educational goals.

\section{References}

Britt, Peggy and Rhonda Hunter. 1994.

Developing and Evaluating Environmental Education Programs. Washington State Department of Ecology Publication \#94-66.

Ham, S. 1992. Environmental Interpretartion. North American Press, Golden, CO.

Jacobson, Susan K. 1999. Communication Skills for Conservation Professionals. Island Press, Washington D.C.

Place, N.T. 2001. Principles of Effective Extension Educational Programs. UF/IFAS Extension publication \#AEC 361 (WC042), http://edis.ifas.ufl.edu/WC042

Regnier, K., Gross, M., and R. Zimmerman. 1994 (third edition). The Interpreters Guidebook: Techniques for programs and presentations. University of Wisconsin-Stevens Point Foundation Press, Stevens Point, WI. 101 pp.

Vella, J.K. 1994. Learning to Listen, Learning to Teach: The power of dialouge in adult education. Jossey Bass, San Fransisco. 